\title{
Salud global en la era de las comunicaciones
}

\section{Global Health in the Communications Age}

\author{
Diego Bernardini \\ (Washington, Estados Unidos) \\ Organización Panamericana de la Salud
}

\section{Cómo citar el artículo}

Bernardini, D. (2012). Salud global en la era de las comunicaciones. Revista de Comunicación y Salud, 2(1), pp. 35-36.

DOI: http://doi.org/10.35669/revistadecomunicacionysalud.2012.2(1).35-36

Quiero inaugurar con este escrito la sección de cartas al editor de la Revista de Comunicación y Salud. Entiendo que las cartas al editor son cruciales en la vida de una publicación periódica, por varias razones:

- Son el combustible que alimenta el diálogo, el debate y el disenso bien entendido, basado en diferentes formas de mirar y estudiar un mismo fenómeno.

- Son el compartir y rebatir las ideas a partir de las evidencias, los interrogantes y las dudas que nos puede dejar la investigación. 
- Son un puente entre quienes conformamos la comunidad científica y académica, desde el cual seguir desarrollando espacios de construcción del conocimiento.

Quiero manifestar en esta carta mi interés porque Revista de Comunicación y Salud aborde en algún momento un tema de gran relevancia presente y futura, como es el de la salud global. La etapa histórica abierta a partir del imperio de la globalización modificó radicalmente dos aspectos constitutivos de las sociedades humanas desde sus primeras expresiones: las nociones de tiempo y espacio. La consecuencia mas tangible fue el 'encogimiento' del espacio geográfico y que el concepto de futuro, que antes se veía como algo lejano, estuviera mucho más cerca del presente.

La salud no escapa a esta profunda transformación. De allí la necesidad de adoptar nuevos enfoques conceptuales y prácticos, para analizar y comprender los determinantes sociales de la salud; la integración multisectorial para enfrentar acontecimientos de envergadura global; o, más específicamente, el abordaje de la comunicación en un tiempo que se define precisamente como la Era de las Comunicaciones, caracterizado por el carácter global e interconectado de la realidad que nos toca vivir.

Frente a esta nueva coyuntura del escenario global, tenemos que buscar respuestas sobre cómo se construyen los vínculos -locales, nacionales, globales- en la gestión de políticas públicas: entre ellos, las referidas al acceso a la salud, los determinantes sociales de la salud, la circulación de la información y el entrenamiento de los profesionales.

La salud global corre el riesgo de hacerse 'demasiado sanitaria' y dejar de lado el concepto de transdisciplinariedad que la globalización impone. Actualmente, en España hay instituciones como la Escuela Andaluza de Salud Pública o la Escuela Nacional de Sanidad que tienen áreas de salud global, y en Barcelona se encuentra el Instituto de Salud Global. Sin embargo, aún vemos que los programas transversales de salud Global, que tanta trascendencia y crecimiento han tenido en países como Estados Unidos, están ausentes en las universidades españolas.

Para mal mayor, estamos en tiempo de crisis y de recortes. Somos muchos los que creemos que las crisis, además de recortes, encierran momentos de oportunidades. Ver la mitad de la copa llena y no la mitad vacía.

Puede que la salud global sea algo demasiado nuevo para que se le preste la atención que se merece en un país en crisis. Revista de Comunicación y Salud puede ayudar a llenar ese vacío, promoviendo la integración transversal del conocimiento para el desarrollo de la salud pública a nivel local y global. Espero que esta carta al editor despierte en los profesionales de la comunicación para la salud una nueva área de interés. Cuanto menos, que sirva para darle vida a un diálogo que, sin dudas, añadirá más valor no sólo a lo publicado en esta revista sino a sus ávidos lectores, entre los que me encuentro. 